\title{
Propositional Attitudes as Commitments: Unleashing Some Constraints
}

\begin{abstract}
Alireza Kazemi ${ }^{1}$
Abstract In a series of papers, Asbjørn Steglich-Peterson $(2008,2011)$ and Nick Zangwill $(2005,2010)$ argue that since propositional attitude (PA) ascription judgments do not behave like normative judgments in being subject to a priori normative supervenience and the Because Constraint, PAs cannot be constitutively normative. This paper argues that for a specific version of normativism, according to which PAs are normative commitments, these arguments fail. To this end, it is first argued that despite their close connection, commitments and obligations should be kept apart. Then it is shown that the intuitions allegedly governing all normative judgments do not even purport to hold for commitment-attributing judgments, including PA-ascription judgments conceived as such. Therefore, these constraints should be constrained to exclude this group of normative judgments.
\end{abstract}

Keywords: Essential Normativity of the Mental, Commitments, The Because Constraint, A Priori Normative Supervenience, Robert Brandom, Propositional Attitudes

\section{Introduction}

Several philosophers have claimed that propositional attitudes (PAs), like beliefs and intentions, are essentially or constitutively normative. ${ }^{2}$ By this, they generally mean that some norms, specifically norms of rationality, should be essentially involved in characterizing the nature of these mental states. For example, it is in the nature of belief that believing $\mathrm{P}$ is correct iff $\mathrm{P}$ is true, or that somebody believing $\mathrm{P}$ should believe its implication if she happens to give any verdict on this, and it is in the nature of intention that intending to $\mathrm{P}$ essentially requires intending the necessary means to P. Let's call this view 'PA normativism'. Irrespective of how this idea may be cashed out, if PAs are essentially or constitutively normative, and it is reflected in their concepts that they are so, then PA-ascription judgments (PAAJ for short), like 'he believes that P', or 'I intend to P' would be normative judgments. As Gibbard (2003) puts it: "when I attribute mental content - when I say, for instance, that Ebenezer is thinking that he has lost his keys-I'm somehow speaking oughts" (p. 85). Starting from this observation, Asbjørn Steglich-Peterson (2008, 2011) and Nick Zangwill $(2005,2010)$ show that PAAJs are not subject to some robust intuitions governing normative thought in general. Having done so, they conclude that PAAJs cannot be normative and, therefore, PAs are not constitutively normative. This is, as far as it goes, a good strategy to determine whether a group of judgments, not obviously normative, are ultimately normative or not. Suppose that something new is discovered. In order to determine whether it is an instance of an entity already known or not, the best way is to check whether the characteristic features of the entity in question apply to this new thing or not. One of the advantages of this argument is that it does not presuppose any specific conception of norms in force for PAs. Whether such norms are conceived as deontic or evaluative (Fassio 2011, McHugh 2012), first-personal or third-personal (Hlobil 2015), as long as PAAJs are normative judgments, this argument works well.

\footnotetext{
${ }^{1}$ Sharif University of Technology (SUT), Iran: ark0069@gmail.com

2 This thesis has recently been defended by Ralph Wedgwood (2011), Alan Millar (2004), Akeel Bilgrami (2004), Paul Boghossian (2003), Alan Gibbard (2003), and Nishi Shah and David Velleman (2005), among others.
} 
This is an early draft of a paper forthcoming in Dialogue: Canadian Philosophical Review. DOI:

https://doi.org/10.1017/S0012217320000098. Please cite the published version.

The widely held intuitions that Steglich-Peterson and Zangwill appeal to are a priori normative supervenience and what Zangwill (2006) has called the Because Constraint (p. 275). ${ }^{3}$ These are wellrespected norms governing normative thought which relate the normative judgments to the non-normative ones. From the observation that PAAJs seem not to be governed by these intuitions, it is concluded that PAs cannot be normative states; they are either non-normative states with nonecessary relation to normative properties (Steglich-Peterson 2008), or non-normative states which essentially consequentially relate to normative requirements (Zangwill 2005, pp. 6-7). To face this line of thought, PA normativists can either try to argue that PAAJs are, after all, subject to such intuitions, properly understood (Laurier 2011), or they may show that these intuitions do not hold for all normative judgments. ${ }^{4}$ In this paper, I grant that these principles do not apply to PAAJs, so the former proposal will not be considered here. ${ }^{5}$ For the latter strategy to be successful, of course, we cannot directly claim that PAAJs are exceptions or counterexamples to these intuitions, because this would be clearly question-begging. A more promising approach is to show that some uncontroversially normative judgments are not subject to these intuitions and then to show that there is a plausible account of PA normativism which precisely construes PAAJs in terms of this kind of normative judgment. It is this strategy which is pursued here. In particular, it will be argued that thinking of PAs as a special kind of commitment, though clearly a version of normativism, has the advantage of matching our intuitions regarding the PAAJs, as well as their divergences from other normative judgments regarding these constraints. ${ }^{6}$

The paper proceeds as follows: section 2 discusses the intuitions allegedly governing all normative judgments and shows how PAAJs diverge from them. Section 3 deals with the attitude-as-commitment model. The distinctness of this view from other versions of normativism is not sufficiently appreciated in the literature: this is because commitment is usually treated as just a different way of speaking about obligations and, as such, its distinguishing features are levelled away. Section 4 addresses this issue and shows that the logic of commitment is interestingly different from the logic of obligations. Having done so, section 5 shows how and why the intuitions discussed in section 2 do not govern commitment-attributing judgments. I finish the paper with a brief conclusion.

\section{Divide and Conquer}

What are the a priori intuitions governing normative judgments? The first one is a priori normative supervenience. According to this, necessarily two objects/properties/persons that are identical in their nonnormative respects, are identical in their normative respects as well. A priori supervenience is, therefore, a coherence constraint. If, for example, this action is damn good, and there is another action which is exactly

\footnotetext{
3 This is also sometimes called 'dependence constraint', see for example Roberts 2017, p. 197.

${ }^{4}$ Note that if the PAs' essential normativity was only known a posteriori, in the same sense that water is essentially $\mathrm{H}_{2} \mathrm{O}$ a posteriori, the fact that PAAJs are not subject to these a priori intuitions could not tell against the essential normativity of PAs. However, it is hard to take such a response seriously, since the main motivation be hind mental normativism is to stress the fact that the norms claimed to be constitutive of PAs do, in fact, contribute to the subject's deliberations and actions self-consciously. Therefore, if we abandon this aspect, by holding that the normativity of PAs may be outside the purview of subjects applying the PA-concept, the thesis loses its initial appeal and "it is hard to see on what grounds anyone would want to hold it" (Laurier, 2011, p. 316, see also SteglichPeterson 2008, pp. 268-69, and Zangwill 2010, p. 29).

${ }^{5}$ For a detailed critique of this proposal, see Steglich-Peterson (2011, 340-44).

6 Thick concepts, like kindness and rudeness, which seem to have descriptive and evaluative contents simultaneously, are sometimes claimed to challenge the Because Constraint (Roberts 2017) and normative supervenience (Roberts 2018) (see Zangwill (2017) for a critique of this idea). The kind of exception to these constraints defended here is, however, completely independent from that line of thought.
} 
This is an early draft of a paper forthcoming in Dialogue: Canadian Philosophical Review. DOI:

https://doi.org/10.1017/S0012217320000098. Please cite the published version.

alike it in all non-normative respects, it would be incoherent to judge that the second action is not damn good (Laurier 2011,pp. 326-27). Note that this is different from any a posteriori supervenience that one might hold about normativity or other subject matters. It is a special feature of normative thought that there is a robust intuition that the supervenience of the normative on the non-normative is conceded a priori. Having this in mind, in the rest of the paper, I will use supervenience and a priori normative supervenience interchangeably.

I follow Zangwill (2006) in calling the next constraint the Because Constraint. According to this, if a subject makes a normative judgment like 'this car is damn good', or 'he ought to do P', she should be ready to back up this judgment by a non-normative one, at least if challenged to do so (p. 270). The nonnormative judgment invoked should show the non-normative property or states of affairs in virtue or because of which the normative judgment holds true. Thus the Because Constraint. This dependence of normative judgments on non-normative ones seems to hold a priori. Namely, somebody who makes a normative judgment but is not ready to ground this judgment by a non-normative one seems to be confused about the meaning of the normative concept she is applying (Steglich-Peterson 2008, pp. 272-73). Suppose somebody says 'this is terrible', but when asked why he thinks so, he replies because this is just terrible. In this case our reaction would be one of surprise and confusion. There ought to be something non-normative making this thing terrible, and the subject making this judgment ought to appreciate this point by being ready to mention this 'something' through a non-normative judgment.

This is unlike empirical judgments which are not usually susceptible to this constraint a priori. In other words, even though we usually ground our empirical judgments, it does not hold a priori that upon making an empirical judgment we should be ready to ground it through another judgment on pain of being confused about the meaning of non-normative concepts we are applying. ${ }^{7}$ Moreover, the kind of grounding relation we have in the Because Constraint is different from other grounding relations. As Steglich-Peterson (2011) stresses, a trace in the sand can ground the judgment that somebody has walked here (p. 342). But it doesn't make any sense to hold that 'somebody has walked here' holds in virtue of the fact that there is a trace in the sand. Therefore, the metaphysical grounding relation that the Because Constraint requires should not be conflated with the evidential support and epistemic grounding that all judgments, normative or otherwise, need to have (Zangwill2017, p. 230). So the Because Constraint is special both in its a priority and also in the specific grounding relation that it claims between the normative and non-normative facts. ${ }^{8}$

Now suppose that PAs are constitutively normative and that this is reflected in their concepts, namely competency in applying PA concepts presupposes respecting their normativity. Therefore, PAAJs are normative judgments and they should be subject to the above-mentioned constraints. Unfortunately, none of these seems to be correct for PAAJs. Regarding the Because Constraint, as Steglich-Peterson(2011) writes: ${ }^{9}$

\footnotetext{
7 I leave it open whether there is also a kind of empirical judgments which is subject to the Because Constraint (Zangwill 2017, p. 239). Note that nothing in the arguments of this paper rests on this.

${ }^{8}$ The link between these two principles is a matter of dispute. Some, like Zangwill (2006) contend that the Because Constraint either is or explains the supervenience (p. 273). Others, like Laurier (2011, pp. 326-27) and SteglichPeterson $(2011,345 n 7)$ think that these two are distinct, even though the Because Constraint is motivated by the supervenience. Nevertheless, in this paper, I address the challenges that supervenience and the Because Constraint pose for PA normativism separately.

${ }^{9}$ Responding to Laurier (2011), Steglich-Peterson has slightly modified his original formulations of the arguments presented in Steglich-Peterson (2008). In this paper, I ignore this dialectic and stick to the latest version of his arguments, as presented in Steglich-Peterson (2011).
} 
This is an early draft of a paper forthcoming in Dialogue: Canadian Philosophical Review. DOI:

https://doi.org/10.1017/S0012217320000098. Please cite the published version.

It is not an a priori requirement that whenever $S$ attributes some attitude, $S$ must be prepared to provide a non-normative judgment in support of it, which satisfies the conditions for non-normative grounding (evidential grounding which does not satisfy those conditions is sufficient) (p. 343).

Unlike normative judgments, like 'this action is despicable', PAAJs do not require a non-normative grounding and are usually self-standing in this respect. One feels no conceptual pressure to ground the judgment 'I believe that P' through a non-normative judgment showing the properties in virtue of which this judgment holds true. PAAJs either require no ground or, when they do, they can be sufficiently grounded through other mental ascriptions. For example, 'I believe that P' can be sufficiently grounded through my belief that $\mathrm{P}^{\wedge} \mathrm{Q}$. But if PAAJs were normative, they could not play the role of a sufficient ground for other PAs. But since they in fact do play such a role, they are not normative judgments (SteglichPeterson 2011, p. 342). As already pointed out, this does not mean that there can be no evidential support for these judgments; things like behavioral clues and assertions (directly or indirectly expressing these attitudes) can, for sure, be evidence for these ascriptions and justify them. But we should distinguish between these evidential supports, present for all judgments, normative or otherwise, and the Because Constraint (Steglich-Peterson 2008, p. 274). It is only on the most implausible behaviorist account of the mind that these behavioral clues are considered as the grounds of PAAJs, in the sense required by the Because Constraint (Steglich-Peterson 2011,p. 342).

The unruliness of PAAJs with respect to this constraint can be discovered from the opposite direction as well. If PAAJs were normative, then:

they could not act as non-normative support for normative rationality judgments in a way that satisfies the Because Constraint. But propositional attitude ascriptions can act as such support. For example, when judging it irrational for $S$ to believe that $p$, it clearly suffices as non-normative support to judge that $S$ believes some other propositions inconsistent with p. (Steglich-Peterson, 2011 p. 335, emphasis original)

Some clarifications are needed so as to make this objection non-question begging (SteglichPeterson 2011, pp. 343-44). There is no denying that normative judgments can ground other normative judgments. As Laurier (2011) points out, the judgment that I ought to open the window can be grounded through the judgment that I ought to let some fresh air in (p. 328). But the grounding normative judgment cannot act as the sufficient ground. For one can again apply the Because Constraint and challenge this new judgment: Why should you let some fresh air in? Because, say, I can hardly breathe in here. The chain of the grounding judgments for normative judgments can include other normative judgments. However, ultimately, a non-normative ground is what ends this chain. And the Because Constraint does not require anything more than that (Zangwill 2017, pp. 323-24). What Steglich-Peterson points out is that, at least sometimes, PAAJs clearly provide a sufficient and self-standing ground for some obviously normative judgments, which are judgments of rationality (Steglich-Peterson 2011, p. 344). Therefore, given the Because Constraint, the PAAJs cannot be normative.

Analogously, Zangwill (2005) points to this in terms of what he calls the problem of "explanatory priority" (P. 7). According to this problem, we tend to explain the rational norms in force for a subject, i.e., what she ought to infer and do, in terms of her PAs, not the other way around. In other words, PAs explain the rational requirements (permissions) governing our thinking and action and it does not make any sense to claim that we have a specific PA because we ought to think and act in a specific way. Rather, we ought to think and act in a specific way because we have a specific PA. Therefore, PAs should not be regarded as 
This is an early draft of a paper forthcoming in Dialogue: Canadian Philosophical Review. DOI:

https://doi.org/10.1017/S0012217320000098. Please cite the published version.

constituted by these norms since these norms are themselves explained by PAs. Added to the remark that these explanations are sufficient and given the Because Constraint, this shows that PAs should be conceived as non-normative states that ground the rational requirements (ibid).

The next divergence between normative judgments and PAAJs concerns a priori normative supervenience. Although the intuition that the normative supervenes on the non-normative is pretty universal, it is not even close to that in the case of PAAJs (Zangwill 2005, p. 7). As Steglich-Peterson (2008) puts it:

whereas the supervenience of the mental on the non-mental is known only a posteriori, the supervenience of the normative on the non-normative is analytic and known a priori. It is a conceptual truth about normative concepts that they are applied on the basis of nonnormative properties. But it is not a conceptual truth that the mental supervenes on the nonmental, and one is not conceptually required to apply mental concepts only on the basis of non-mental properties ... In other words, even if propositional attitudes in fact supervene on non-mental, non-normative properties, this is not an a priori truth that one would display conceptual incompetence in denying. (p. 274, emphasis original)

The fact that PAs supervene on natural facts (particularly brain states) is almost an orthodoxy in the contemporary philosophy of mind. But few, if any, would claim that there is an a priori intuition behind that. No incoherence seems to follow if I do not have a specific belief or intention which I do in another situation identical in all non-normative respects. Millions of people, Zangwill (2010) says, believe that mind can survive the death of body or that mind supervenes on nothing other than itself. It is implausible to hold that all of these people are denying an a priori intuition about the mind (pp. 28-29), as they would be in rejecting the normative supervenience. This asymmetry, according to this line of thought, betrays the nonnormativity of PAAJs (Steglich-Peterson 2008, p. 274).

Given all these, should we conclude, along with Zangwill and Steglich-Peterson, that PAAJs are non-normative? In the remaining sections, it is argued that it is so soon to succumb to these arguments.

\section{Attitudes as Commitments}

Conceiving propositional attitudes, particularly beliefs and intentions, as special kinds of commitments is a pretty recent idea in the literature put forward by a group of normativists. Although Wilfrid Sellars sometimes suggested this conception (see for example, Sellars 1967, p. 3), it was Robert Brandom (1994) whofirst worked out this idea in great detail in his magnumopus, Making it Explicit. Quite independently and with some differences, this idea has been defended by Isaac Levi (2002), Richard Moran (2001), Alan Millar (2004, 2009), Akeel Bilgrami (2004, 2006), Thomas Baldwin (2007), Annalisa Coliva (2016) and Nicholas Tebben $(2018,2019)$. Fortunately, the argument of this paper is not affected by the differences between these characterizations and works for all of them. However, for the sake of brevity, I focus on Brandom's characterization of this thesis and just point to others when it helps to clarify the issues. $^{10}$

Commitment is in no way an unfamiliar category; in our ordinary life we are all familiar with such a notion. Promising is the paradigmatic case of undertaking a commitment towards somebody to fulfill something (Searle 1964, p. 45, Brandom 1994, pp. 163-65, Millar 2004, p. 72). Signing a contract is another

${ }^{10}$ Coliva (2016) and Tebben (2018) think that belief is ambiguous between commitments and internal psychological states. Brandom (1994) puts great emphasis on the social nature of commitments. But others think that the firstpersonal perspective is more fundamental to commitments. 
This is an early draft of a paper forthcoming in Dialogue: Canadian Philosophical Review. DOI:

https://doi.org/10.1017/S0012217320000098. Please cite the published version.

example of undertaking a commitment. By undertaking a commitment, a subject incurs a responsibility to live up to the commitment and authorizes others to count on this. Therefore, commitment is clearly a normative concept, in the sense that there is no way to specify commitments non-normatively. ${ }^{11}$ Brandom (1994) suggests we replace beliefs and intentions with doxastic and practical commitments respectively, which he collectively calls discursive commitments (p. 159). ${ }^{12}$ For him, commitments can do all the explanatory work expected from intentional states (ibid).

It should be noted that different kinds of commitments may vary in what they make the subject committed to. In the case of promising, it is doing what one has promised that is the object of the commitment. What is it that the subject is committed to in having PAs? To start with, PAs are "commitments to think various things and to do various things" (Bilgrami, 2004, p. 128). Discursive commitments, for Brandom, are inferentially articulated commitments, i.e., commitments to have other commitments determined by the inferential status of the object of the commitment. Entertaining a belief that $\mathrm{P}$ is undertaking a commitment to the truth of $\mathrm{P}$. By undertaking this commitment a subject incurs the responsibility to defend $\mathrm{P}$, when challenged, by providing reasons which are other commitments, ${ }^{13}$ and to be committed to the implications of this commitment. For example, by being committed to 'it is red', a subject becomes committed to 'it is colored' (this is what Brandom calls a "commitment-preserving inferential relation" (p.168)), and she should be ready to defend this commitment, for example, by invoking her reliability in discerning the colors. Similarly, intentions are modeled as practical commitments to make something happen. Undertaking practical commitments is also inferentially articulated in terms of meansend relations (I intend to go to the shop and getting on the bus is the only way available, so I have to get on the bus), and incompatibility relations (I should not be committed to read this book now, if I don't know how to read) (Brandom, 1994, pp. 233-34). However, compared with promises, intentions are looser commitments in the sense that, unlike the case of promising, the subject can easily abandon them, usually without any criticism. But as long as she holds the intention, she ought to respect these obligations. As Millar (2004) puts it, "I can discharge this commitment in one of two ways: by doing the necessary, or by giving up the intention" (p.75).

In parallel with the normative category of commitment, Brandom puts forward the normative category of entitlement, by which he means permission or right. These are two primitive deontic statuses which are irreducible yet complementary: "Doing what one is committed to do is appropriate in one sense, while doing what one is entitled to do is appropriate in another" (Brandom, 1994, p. 159). Therefore, entitlement to one's commitments is another normative dimension that opens up when we construe PAs as commitments. As mentioned above, vindicating one's entitlement to beliefs (doxastic commitments), when properly challenged, is one of the responsibilities that a subject incurs when undertaking a doxastic

\footnotetext{
11 That commitment, at least in the sense used here, is a normative concept is, I think, as obvious as the related concepts like responsibility, authority and entitlement are. I, therefore, take it for granted and do not argue for it here. However, as Millar (2004, p. 72) and Tebben (2019, p. 323) rightly point out there is a non-normative sense of commitment as well according to which being committed to something is being resolved, determined or dedicated to do something. It is clear that the sense drawn on in the attitude-as-commitment model is the normative sense.

12 Brandom (1994) is clear that he does not intend to analyze or reduce beliefs to commitments. His proposal is to give up the belief-talk altogether and replace it with commitment-talk (p. 196). This further move is not, however, required for the arguments of this paper.

13 This, of course, does not mean that we are under obligation to stubbornly defend our beliefs. What this means is that the subject is under obligation to be sensitive to the challenges leveled against her commitments. Sometimes it is by abandoning the commitment that this can be done. I suspect that Bilgrami $(2004$, p. 137$)$ has misunderstood the significance of this point.
} 
This is an early draft of a paper forthcoming in Dialogue: Canadian Philosophical Review. DOI: https://doi.org/10.1017/S0012217320000098. Please cite the published version.

commitment. Further, by undertaking a commitment a subject becomes entitled to many other commitments which may not be available to her beforehand. For example, by undertaking a commitment to 'this is a dry match', I become entitled to the commitment 'this will light if struck', even though I am not compelled to accept that (this is what Brandom calls an "entitlement-preserving inferential relation" (p. 168)). Given all these, Brandom defines two incompatible commitments as those in which commitment to one precludes entitlement to the other (p. 169). 'It is red' and 'it is colorless' are incompatible, since by undertaking the former a subject loses her entitlement to the latter. Of course one can have commitments to which one is not entitled: the dimension of entitlement disallows this, but does not make it impossible. ${ }^{14}$

Commitments for Brandom cannot be separated from the practical attitudes of attributing and undertaking them. In fact, Brandom (1994) thinks that commitments are the creatures of the social practice of attributing/undertaking them (p. 161). Even if we deny this strong claim, it is still plausible that commitments are alway saccompanied by these practical attitudes. There are no free-floating commitments; they should be either undertaken or attributed to someone.

What makes the commitment-model of beliefs unappealing to many is that it seems to contradict the widely held view known as doxastic involuntarism: according to this view, beliefs are involuntary in the sense that the subject does not decide to have them. In this se nse, beliefs are obviously not like promises, intentions, and even assertions whose forming is clearly voluntary. And since beliefs are involuntary, the objector continues, they cannot incur responsibility; one cannot be deemed responsible for what one has no control over. Therefore, it does not make any sense to construe beliefs as commitments. This objection, however, misfires. True, doxastic commitments can be involuntary. I open my eyes and come to believe many things (to undertake doxastic commitments). Nevertheless, my responsibility now does not concem the formation of belief. Granted, I should not be responsible for something that I have no control over, but my responsibilities here do not concern this; rather, by coming to believe something, I incur a responsibility to follow the consequences of my beliefs and to defend the belief if challenged, namely if shown to be incompatible with my other commitments. If I cannot successfully defend the commitment, probably by abandoning the commitments incompatible with it or by showing that the challenge is not well-placed, I lose my entitlement to it and I should not undertake this commitment anymore. Therefore, even though unlike the cases of promising and signing a contract, doxastic commitments are not usually voluntary, this does not mean the responsibility dimension goes away. The involuntariness and the responsibility each concern different dimensions and, as such, do not undermine each other. In the case of promising, I am both responsible for making the promise and living up to it. But in the case of belief, it is holding the belief (not its formation) that my responsibility consists in. ${ }^{15}$

It may seem that this view is nothing but anotherway to explicate the thesis that PAs are constituted by rational requirements and obligations. If this is so, then we will end up just where we started; PAAJs sufficiently explain the rational obligations and as such they should be non-normative judgments. Moreover, unlike evaluative and deontic judgments, PAAJs do not conceptually cry out for a metaphysical ground. Unfortunately, the defenders of this view have not done enough to dispel this thought. But the relationship between commitments and obligations is more subtle. Identifying these two normative

14 Further to the intrapersonal dimension of commitments, which concerns one subject's concomitant commitments, Brandom (1994) also puts forward the interpersonal dimension, which concerns the normative role that my assertion (expressing my belief) essentially plays for other people (pp. 169-70). Interesting as it may be, this dimension does not concern us here.

15 for a similar remark, see Baldwin 2007, p. 83. For a different strategy, see Tebben 2018. 
This is an early draft of a paper forthcoming in Dialogue: Canadian Philosophical Review. DOI:

https://doi.org/10.1017/S0012217320000098. Please cite the published version.

categories makes us lose sight of the specific logic of the commitments, along with their undertaking/attribution. The next section tries to bring this important point home.

\section{Commitments and Obligations}

What is the relationship between commitment and obligation? To begin with, being committed to something is not identical with being obliged to do something. Rather, undertaking commitments explains the obligations that a subject becomes subject to. Unfortunately, even Brandom (1994) sometimes writes in a way that seems to urge the contrary. For him, commitments are just another way of speaking about obligations; a way that does not imply the hierarchical picture of obliging others implicit in the concept of obligation (p. 160). But this cannot be true; I should see my friend because I have promised him to do so, but it is not the case that I have promised to see him because I should see him. It is the same when we attribute a commitment to somebody else; that she is committed to $\mathrm{P}$ is not identical with the claim that she ought to $\mathrm{P}$, even though this obligation conceptually stems from the commitment in question. Therefore, even though undertaking commitments essentially imposes some obligations on the subject, commitments cannot be identified with such obligations. There is a unidirectional path from commitments to the course of action that should be done as a result of undertaking them. Accordingly, if belief or intention is a specific kind of commitment, as suggested in the previous section, this does not mean that beliefs or intentions are a cluster of obligations or (rational) requirements imposed on the subject. Rather, they are commitments whose undertaking/attribution essentially enjoins some responsibility to comply with these obligations. Therefore, the rational norms essentially in force for PAs are responsibilities that a subject incurs as a result of undertaking these commitments. This point is analogous to Zangwill's explanatory priority objection to conceiving PAs as normativestates discussed in the previous section. Commitments explain the obligations, not the other way around. Therefore, these two cannot be identical.

There is another related reason as well; obligations can be defined in terms of permissions. Brandom (1994) is right that doing so presupposes the formal notion of negation, but still this move is successful (p. 160). 'I am obliged to do P' can be defined as 'I am not permitted not to do P'. However, even with such a presupposition, commitments cannot be defined in terms of entitlements (rights, permissions). Brandom (1994) says that "It does make sense to think of being committed to do something as not being entitled not to do it" (ibid). But this cannot be right. It is true that I am not entitled not to x $a s$ a result of being committed to $\mathrm{x}$; but it is clearly different from defining the commitment in terms of the entitlement. Intuitively, I may not be permitted not to $\mathrm{x}$ but still bear no commitment to $\mathrm{x}$. But if I have undertaken a commitment (or am legitimately attributed one), I would not be entitled not to do it. This is not, however, a case of defining commitments in terms of entitlements. Rather, the consequent of this conditional holds because, as a result of undertaking a commitment, I come under an obligation to fulfill $\mathrm{x}$, which now means that I would not be entitled not to do it.

Notice that undertaking a commitment is not acknowledging an obligation either. I may not accept that I ought to stop smoking. But when I accept that, this still does not amount to undertaking a commitment to do so. There is an extra ingredient to undertaking a commitment. Obligations ensuing from commitments are, so to speak, self-imposed obligations (Liberman and Shroeder 2016); to be committed to stop smoking, I should have bounded myself to do so. This is not only acknowledging that a norm is in force for me, but also creating this norm $a b$ initio. ${ }^{16}$ In this sense, Bilgrami (2006) seems right that there is an "agential" or

${ }^{16}$ One may object that undertaking a commitment is just thinking that one is obliged to do something, not that one is really obliged to do something. I think a little reflection will show that this is wrong; there is an obvious gap between thinking that one is obliged and being really obliged. However, undertaking a commitment is making oneself obliged, namely it creates an obligation (for a similar remark see Searle 1964, p.46). 
This is an early draft of a paper forthcoming in Dialogue: Canadian Philosophical Review. DOI:

https://doi.org/10.1017/S0012217320000098. Please cite the published version.

"performative" aspect to commitments (p. 63). Commitments are specific to rational beings who can autonomously bound themselves and incur responsibilities. Therefore, only an agent or human subject can bear commitments. Finally, it is clear that undertaking a commitment does not mean that the subject will discharge it. The only link between undertaking a commitment and discharging it is that the subject should discharge the commitment that she has undertaken on pain of being criticized for her failure. The link, therefore, is itself normative through and through. ${ }^{17}$

I conclude that despite their close connection, commitments should not be identified with obligations. ${ }^{18}$ By identifying commitments with obligations we lose sight of the distinguishing features of commitment-talk. The importance of these features will become salient in the next section when we see how commitment-attributing judgments differ from other normative judgments, including many obligationattributing judgments, with respect to the intuitions discussed in section 2 .

\section{Commitments vs. the Intuitions}

Finally, let's see how this normative account of PAs confronts the intuitions discussed in section 2. This section aims to show that when it comes to commitments, these intuitions do not even purport to hold. Let's start with a priori normative supervenience. Interestingly, in a rather different context, Bilgrami (2006) has noticed that commitments, including PAs construed as such, are not subject to the a priori supervenience relation. As he puts it:

two worlds may be exactly alike in descriptive facts but not in performative facts ... Supervenience is not a thesis that is made for, made to fit, the performative aspect of promising. Whatever it fits, it does not fit the performative aspect. That is exactly analogous to the point about the supervenience of values or of intentionality (thought of as values or commitments) on non-evaluative facts. ${ }^{19}$ (p. 63)

Consider the idealized case of promising again. Suppose you have undertaken a commitment to somebody. Now, there seems to be no a priori pressure to concede that necessarily in a situation exactly alike this in all non-normative respects, you would have undertaken the same commitment or any commitment at all. Therefore, it seems that we have no intuition of supervenience of commitments on nonnormative facts, similar to what we lack in the case of PAs. No incoherence seems to follow if I have a different set of commitments in a situation exactly alike in all non-normative respects. At least when considered a priori, commitments seem to be independent with respect to non-normative facts, and the changes thereof. True, at least when it comes to doxastic commitments, having incompatible commitments (about a non-normative state of affairs) in non-normatively indiscernible situations can challenge the entitlement of the subject to those commitments. But this is different from supervenience and also holds for beliefs; having inconsistent beliefs (about a non-normative state of affairs) in two non-normatively indiscernible situations challenges the rationality of the beliefs. But it does not mean that beliefs supervene a priori on natural facts.

How about the Because Constraint? Let's start with the explanatory priority objection that Zangwill raised against PA normativism. The commitment-model of PAs behaves exactly similarly in this respect; I

\footnotetext{
${ }^{17}$ For a similar remark, see Steglich-Peterson, 2006, pp. 506-7.

18 For an interesting discussion on commitment and its distinguishing features, see Shpall 2014.

19 Notice that the kind of supervenience Bilgrami is appealing to here is global supervenience. Unlike weak supervenience which compares two situations in a single world, global supervenience concerns two distinct possible worlds. Therefore, global supervenience has a modal force which weak supervenience lacks. For a recent discussion of different kinds of supervenience and their implications for normativity, see Roberts 2018.
} 
This is an early draft of a paper forthcoming in Dialogue: Canadian Philosophical Review. DOI:

https://doi.org/10.1017/S0012217320000098. Please cite the published version.

ought to infer such and such because I am committed to P. I ought to do such and such because I've promised you to do so. Therefore, the explanatory priority objection has nothing to tell against seeing PAs as commitments, even though it might be effective against other versions of normativism. This is so because, as we saw, commitments create and explain the obligations they impose. Further, commitmentattributing judgments are sufficient for grounding judgments of rationality as well: it is irrational for you to be committed to $\mathrm{Q}$ because you are committed to $\mathrm{P}$ which is incompatible with it. Intuitively, these are sufficient explanations in the sense that nothing more is expected. Moreover, this goes beyond saying that commitments can sufficiently explain each other (as PAs can do); I am committed to P, because I am committed to $\mathrm{P}^{\wedge} \mathrm{Q}$.

Finally, like PAAJs, attributing/undertaking commitments does not require non-normative grounding in the sense demanded by the Because Constraint (other than innocuous evidential support like expressions and behavioral clues). You are committed to $\mathrm{P}$, because you have just said so, or you are behaving in a way that entitles such an attribution; these are epistemic reasons for attributing commitment, but it does not make any sense to claim that I am committed to $\mathrm{P}$ in virtue or because of a non-normative fact like behaving in a specific way. ${ }^{20}$ It is a priori that there should be something grounding why this car is damn good, like the fact that it is fast and cheap. But there is no such an a priori requirement for 'Tom believes that P' or 'Tom is committed to P'. This is so because, as we saw in the previous section, commitments are special normative statuses that autonomous beings are capable of undertaking. Undertaking commitments is to bind oneself to a specific course of action, to make oneself responsible to do something. Commitments create obligations and nothing further to the fact that a commitment is undertaken is required to explain the obligations that the subject has incurred as a result of them.

Even though these constraints do not govern commitments, it should not be concluded that commitments are worryingly ungrounded. Commitments can and should be challenged and reasons can always be asked for them. As already discussed, this is what the orthogonal dimension of entitlement provides for commitments. But commitment-attributing judgments do not hold in virtue or because of their entitlement. The relation between the commitments and their entitlement is not like the relation between the normative judgments and their grounding non-normative ones. I may be committed to something and, happily, I may have entitlement to it. But I also may be committed to something without being entitled to it, in which case I ought to revise my commitment.

As should be clear by now, as well as the commitment-attributing judgments which are not subject to the constraints, some normative judgments stemming from commitment-attributing judgments are not governed by these constraints either. We saw that deontic judgments stemming from commitments (e.g., you ought to see me because you have promised me to do so) can be sufficiently grounded through commitment-attributing judgments which are normative judgments. Therefore, the Because Constraint does

\footnotetext{
${ }^{20}$ We say that I am committed to this because I have signed this contract. Isn't it a grounding relation? I don't think so. This explanation is more like I am committed to this because I have promised you to do so. Promising and signing documents are undertaking commitments, not non-normatively specifiable actions that enjoin commitments. Signing, contracting, agreement, and promising are all normatively-charged words presupposing the practice of undertaking and attributing commitments (Searle 1964, p. 56). When these actions are detached from this practice, for example once they are considered as depositing some ink on the end of a paper or making some noises, this illusion disappears. For the same reason, we should make sure that we are not including these normative respects into the supervenience base in thinking about non-normatively identical situations. I am committed to P because I have signed this contract. Of course, in a non-normatively indistinguishable situation in which I have signed this contract, I would be committed to P. But this situation is not only non-normatively identical, but also has part of the normative properties of the first situation. So it cannot show that commitments supervene.
} 
This is an early draft of a paper forthcoming in Dialogue: Canadian Philosophical Review. DOI:

https://doi.org/10.1017/S0012217320000098. Please cite the published version.

not apply to this group of normative judgments either. If we have axiological (evaluative) judgments that can be grounded through commitment-attributing judgments, they also will be exceptions to these constraints. Suppose that I violate a commitment that I have made to you which you have counted on wholeheartedly, say that I will come to the cinema with you. This action, namely not coming to the cinema with you, is bad because it violates the commitment that I have undertaken toward you. Various nonnormative facts can contribute to the degree of badness of this action - if, for example, counting on my commitment, you have prepared many things which will be ruined by my violating my commitment. Despite this, the fact that this action is bad requires no more grounding than that it is a breaking of my commitment. And this sufficient ground is normative through and through.

It might be tempting to think that something more is needed here. Why is this action a violation of my commitment? Because it is (or implies) my not coming to the cinema. So, perhaps it is this 'not coming to the cinema' in virtue of which this action is wrong. But I contend that we should resist such a temptation. Coming/not coming to the cinema specifies the condition of fulfillment/transgression of the commitment undertaken. It is clear that no commitment can be made unless its conditions of fulfillment are, at least implicitly, specified. Moreover, the conditions of fulfillment can, for sure, be expressed using nonnormative judgments. But we should note that these non-normative judgments just show why a specific commitment is fulfilled or violated, not why the commitment in question is undertaken or attributed or why violating the commitment is wrong. Conflating these two can lead us to think that these non-normative judgments are what the Because Constraint requires. Now consider again the judgment that your action in not coming to the cinema is bad. As I argued, this judgment can be sufficiently grounded through the fact that this action is against the commitment you have undertaken. You ought to do what you have committed to do and, therefore, it would be wrong not to fulfill your commitments. Granted, we can ask why this violates your commitment, and now you should invoke the non-normative judgment specifying the condition of fulfillment of the commitment undertaken. ${ }^{21}$ The non-transitivity from 'this action is bad because it is against your commitment' and 'this action is against your commitment because it is your not coming to the cinema' to 'this action is bad because it is your not coming to the cinema' is, I contend, a signal that the second sense of because is not what we have in the Because Constraint. ${ }^{22}$ This is bad only because it is a violating of my commitment. But it violates my commitment because it is (or implies) not coming to the cinema.

If this is right, then commitment-attributing judgments can sometimes sufficiently back up evaluative judgments regarding actions and states of affairs as well, just as they can back up certain requirements that apply to the subject. This shows that beside the commitment-attributing judgments, the Because Constraint should further be constrained to exclude those normative judgments (deontic or evaluative) that can be explained through them. Accordingly, these commitment-grounded judgments are

\footnotetext{
${ }^{21}$ Although I cannot fully defend it here, I think that institutional rules (like those in sports) are exceptions to these constraints too. Both Steglich-Peterson (2008, p. 275) and Zangwill (2017, p. 223) stress that the judgment that an action is foul in football should be grounded non-normatively, e.g., through the judgment that, say, 'you touched the ball with your hand', and this bears witness to the Because Constraint. But I think 'it is a foul' is sufficiently grounded through the judgment that it is against the rule that the players have committed themselves to obeying by entering the game of football'. And 'touching the ball with your hand' is the condition of fulfilment/transgression of the rule, not what makes for any normative property. Of course the player can be (or pretend to be) ignorant about the rule that she has transgressed and, therefore, she can question this judgment. But this is not asking for the non-normative property or fact in virtue of which the action is wrong. The wrongness of this action presupposes this rule and cannot explain it.
} 
This is an early draft of a paper forthcoming in Dialogue: Canadian Philosophical Review. DOI:

https://doi.org/10.1017/S0012217320000098. Please cite the published version.

not susceptible to supervenience either. For example, given an action that is bad because it violates your commitment and another action exactly alike in all non-normative respects, the second action might not be bad because there might be no commitment in play in the second case. Similarly, I ought to do something, because I have undertaken a commitment to do so. Now since commitments do not supervene a priori on non-normative properties, in a situation that is non-normatively indiscernible it does not follow a priori that I should have undertaken the same commitment, and therefore it does not follow that I ought to do the thing in question.

I conclude that commitment-attributing judgments are as detached from these a priori constraints as PAAJs seem to be. So it is not bad news for PA normativists, at least in the version under consideration, that these constraints do not apply to PAAJs, since they also do not apply to commitment-attributing judgments which are normative through and through.

\section{Conclusion}

This paper argued that, despite their close connection, it is a mistake to identify the familiar normative category of commitment with obligations and requirements. When we respect the special logic of commitments, it becomes salient that commitment-attributing judgments, though indisputably normative, are not subject to certain robust intuitions governing other normative judgments. Therefore, it is just Wittgenstein's one-sided diet which leads us to claim that these constraints hold for all normative judgments. These constraints should be constrained to exclude commitment-attributing judgments and those normative judgments stemming from them. One could yet dig in and insist that commitments are nonnormative because they are not subject to these constraints, but given that these constraints are themselves based on commonsense intuitions, this move does not seem plausible. Surprisingly, we saw that there is a version of PA normativism in which PAs are construed as specific kinds of commitments. We saw that the commitment-model of PAs is prima facie faithful to our intuitions regarding PAAJs as well as their divergences from other normative judgments. In view of this, the whole project of dividing PAAJ from normative judgment through these intuitions cannot get off the ground. Although this version of PA normativism is developed for quite independent considerations from those discussed here, the fact that this corresponds to the divergences that PAAJs show with respect to other normative judgments, lend sit support over its rivals. Therefore, even though what Zangwill and Steglich-Peterson provides might have force against many versions of PA normativism, it has no bite against the attitude-as-commitment model.

\section{References}

Baldwin, T. (2007) The Normative Character of Belief. In M. Green, \& J. N Willaims (Eds.). Moore's Paradox: New Essays on Belief, Rationality, and the First Person (pp. 76-89). New York: Oxford University Press.

Bilgrami, A. (2004). Intentionality and Norms. In M. De Caro \& D. McArthur (Eds.), Naturalism in Question (pp. 125-51). London, England: Harvard University Press.

Bilgrami, A. (2006). Some Philosophical Integrations. In C. Macdonald \& G. Macdonald (Eds.), McDowell and His Critics (pp. 50-65). Oxford: Blackwell Publishing.

Boghossian, P. (2003). The Normativity of Content. Philosophical Issues, 13(1), 31-45.

Brandom, R. (1994). Making it Explicit: Reasoning, Representing, and Discursive Commitment. Cambridge (MA): Harvard University Press.

Coliva, A. (2016). The Varieties of Self-Knowledge. London: Palgrave Macmillan.

Fassio, D. (2011). Belief, Correctness and Normativity. Logique et Analyse , 54(216), 471-486.

Gibbard, A. (2003). Thoughts and Norms. Philosophical Issues, 13(1), 83-98 
Hlobil, U. (2015). Anti-Normativism Evaluated. International Journal of Philosophical Studies, 23(3), 376-95.

Laurier, D. (2011). Intentional Normativism Meets Normative Supervenience and the Because Constraint. Dialogue: Canadian Philosophical Review, 50(2), 315-31.

Levi, I. (2002). Commitment and Change of View. In J. L. Bermudez \& A. Millars (Eds.). Reason and Nature, Essaysin the TheoryofRationality (pp. 209-232). New York: Oxford University Press.

Liberman, A., \& Shroeder, M. (2016). Commitments: Worth the Weight. In E. Lord \& B. Maguire (Eds.). Weighing Reasons (pp. 104-121). Oxford: Oxford University Press.

McHugh, C. (2012). The truth norm of belief. Pacific Philosophical Quarterly, 93(1), 8-30.

Millar, A. (2004). Understanding People: Normativity and Rationalizing Explanations. New York: Oxford University Press.

Millar, A. (2009). How Reasons for Action Differ from Reasons for Belief, In S. Robertson (Ed.), Spheres of Reasons: New Essays in the Philosophy of Normativity. (pp. 140-63). New York: Oxford University Press.

Moran, R. (2001). Authority and Estrangement: An Essay on Self-Knowledge. Oxford: Princeton University Press.

Roberts, D. (2017). Depending on the Thick. Aristotelian Society Supplementary Volume, 91(1), 197220

Roberts, D. (2018). Why Believe in Normative Supervenience? In R. Shafer-Landau (Ed.), Oxford Studies in Metaethics 13 (pp. 1-24). Oxford: Clarendon Press

Searle, J. R. (1964). How to derive 'ought' from 'is'. The Philosophical Review 73, 43-58.

Sellars, W. (1967). Form and Content in Ethical Theory. The Lindley Lecture. Department of Philosophy, University of Kansas.

Shah, N., \& Velleman, D. (2005). Doxastic Deliberation. The Philosophical Review, 114, 497-534.

Shpall, S. (2014). Moral and Rational Commitment. Philosophy and Phenomenological Research, $88(1), 146-172$

Steglich-Petersen, A. (2006). No Norm Needed: on the Aim of Belief. The Philosophical Quarterly, 56(225), 499-516.

Steglich-Petersen, A. (2008). Against Essential Normativity of the Mental. Philosophical Studies, 140, 263-83.

Steglich-Petersen, A. (2011). Against Essential Mental Normarivity Again. Dialogue: Canadian Philosophical Review, 50(2), 333-46.

Tebben, N. (2018). Belief isn't Voluntary, but Commitment is. Synthese, 195(3), 1163-1179.

Tebben, N. (2019). Knowledge Requires Commitment (Instead of Belief). Philosophical Studies, 176(2), 321-338.

Wedgwood, R. (2011). The Normativity of the Intentional. In B. P. McLaughlin, A. Beckermann \& S. Walter (Eds.), The Oxford Handbook of Philosophy of Mind. (pp.421-436). New York: Oxford University Press.

Zangwill, N. (2005). The Normativity of the Mental. Philosophical Explorations, 8(1), 1-19.

Zangwill, N. (2006). Moral Epistemology and the Because Constraint. In J. Dreier (Ed.), Contemporary Debates in Moral Theory. (pp. 263-282). Oxford, UK: Blackwell Publishing.

Zangwill, N. (2010). Normativity and the Metaphysics of Mind. Australasian Journal of Philosophy, 88(1), 21-39.

Zangwill, N. (2017). Moral Dependence and Natural Properties. Aristotelian Society Supplementary Volume, 91(1), 221-243. 
This is an early draft of a paper forthcoming in Dialogue: Canadian Philosophical Review. DOI: https://doi.org/10.1017/S0012217320000098. Please cite the published version. 